interval $(\mathrm{Cl}) 1.2-35 ; \mathrm{p}=0,026)$ and presence of nodular conglomerates (OR 4,8; CI $1.4-16.1 ; p=0.01$ ) were the key predictors of ground glass opacity (GGO) CT phenomenon. In $90 \%$ of patients EN did not relapse, and articular syndrome almost completely regressed during 1 year follow-up.

Conclusions: Patients with an acute form of sarcoidosis require coordinated action of different medical specialties, including rheumatologists, to determine the scope of further examination and adequate therapeutic regimen.

Disclosure of Interest: None declared

DOI: 10.1136/annrheumdis-2018-eular.2094

\section{THU0634 RISK OF SUDDEN CARDIAC DEATH IN PATIENTS WITH SARCOIDOSIS: A POPULATION-BASED RETROSPECTIVE COHORT STUDY}

A.A. Chahal ${ }^{1}$, P.A. Brady ${ }^{1}$, C.S. Crowson ${ }^{2}$, V.K. Somers ${ }^{1}$, E.L. Matteson ${ }^{2}$, P. Ungprasert ${ }^{3}$. ${ }^{1}$ Cardiovascular Diseases; ${ }^{2}$ Rheumatology, Mayo Clinic, Rochester, USA; ${ }^{3}$ Research and development, Faculty of Medicine Siriraj Hospital, Mahidol University, Bangkok, Thailand

Background: Sarcoidosis is an inflammatory, non-caseating, granulomatous disorder of unknown etiology which can affect any body system including the heart and can be associated with increased risk of cardiovascular disease including sudden cardiac death (SCD). However, the risk and incidence of SCD are unknown.

Objectives: We sought to determine whether the risk of SCD in patients with sarcoidosis is higher than in the general population.

Methods: A population-based cohort of 345 incident cases of sarcoidosis $(50 \%$ female; $90 \%$ Caucasian, 5\% African-American; mean age 45.6 years) among Olmsted County, Minnesota residents in 1976-2013 was identified from a comprehensive medical record-linkage system. Medical records of those cases were individually reviewed to confirm the diagnosis of sarcoidosis which required physician diagnosis supported by histopathology, compatible clinical presentation and exclusion of other granulomatous diseases. A total of 345 sex and age-matched comparators $(50 \%$ female; $95 \%$ Caucasian, $1 \%$ African-American; mean age 45.4 years) were also identified from the same underlying population. Mortality, including time, place and cause of death of cases and comparators were individually reviewed for SCD events. SCD incidence rates are reported per 100000 person-years and Cox proportional hazards models were used for comparisons between groups.

Results: The median length of follow-up was 12.9 (6.0-23.4) years and 15.8 (6.8-25.5) for cases and comparators, respectively. Of the 58 deaths in patients with sarcoidosis, 10 were due to definite/probable SCD, versus 57 all-cause and 9 definite/probable SCDs in comparators. Incidence rate of SCD in sarcoidosis was 192 per 100000 person-years (PY) (95\% confidence interval $(\mathrm{Cl}), 92-352)$ versus 155 per $100,000 \mathrm{PY}(95 \% \mathrm{Cl}, 71-294)$ in comparators, corresponding to the hazard ratio of $1.28(95 \% \mathrm{Cl}, 0.52-3.17, \mathrm{p}=0.59)$. Analysis by time of $\mathrm{SCD}$, sex, age, calendar year of incidence/index date also did not reveal a significantly different rate of SCD between the 2 groups as demonstrated in table 1 .

\begin{tabular}{|c|c|c|c|c|c|}
\hline Category & $\begin{array}{l}\text { Number of deaths } \\
\text { in sarcoidosis/non- } \\
\text { sarcoidosis }\end{array}$ & $\begin{array}{l}\text { Rate per } 100,000 \\
\text { PY in sarcoidosis } \\
\quad(95 \% \mathrm{Cl})\end{array}$ & $\begin{array}{l}\text { Rate per } 100,000 \\
\text { PY in non- } \\
\text { sarcoidosis } \\
(95 \% \mathrm{Cl})\end{array}$ & $\begin{array}{c}\text { Hazard } \\
\text { Ratio } \\
(95 \% \mathrm{Cl})\end{array}$ & $\begin{array}{c}\mathrm{p}- \\
\text { value }\end{array}$ \\
\hline $\begin{array}{l}\text { SCD at } \\
\text { night } \\
(22: 00- \\
06: 00)\end{array}$ & $3 / 1$ & $57(12-168)$ & $17(0.4-95)$ & $\begin{array}{c}3.76 \\
(0.39- \\
36.47)\end{array}$ & 0.25 \\
\hline $\begin{array}{l}\text { SCD at } \\
\text { day }\end{array}$ & $6 / 6$ & $115(42-250)$ & $103(38-224)$ & $\begin{array}{c}1.16 \\
(0.37- \\
3.60)\end{array}$ & 0.80 \\
\hline $\begin{array}{l}\text { SCD an } \\
\text { unknown } \\
\text { time }\end{array}$ & $1 / 2$ & NA & NA & NA & \\
\hline Females & $6 / 6$ & $217(79-471)$ & $205(75-447)$ & $\begin{array}{c}1.12 \\
(0.37- \\
3.47)\end{array}$ & 0.85 \\
\hline Males & $4 / 3$ & $163(44-418)$ & $103(21-302)$ & $\begin{array}{c}1.49 \\
(0.33- \\
6.69)\end{array}$ & 0.60 \\
\hline $\begin{array}{l}\text { Age: } 18- \\
39 \text { years }\end{array}$ & $0 / 0$ & 0 & 0 & NA & \\
\hline $\begin{array}{l}\text { Age: } 40- \\
59 \text { years }\end{array}$ & $2 / 0$ & $76(9-275)$ & 0 & NA & \\
\hline $\begin{array}{l}\text { Age: } 60 \\
\text { +years }\end{array}$ & $8 / 9$ & $450(194-886)$ & $470(215-895)$ & NA & \\
\hline $\begin{array}{l}1976- \\
1994\end{array}$ & $3 / 3$ & $259(54-756)$ & $228(47-666)$ & NA & \\
\hline
\end{tabular}

$\begin{array}{llrrr}1995- & 1 / 2 & 62(2-345) & 110(13-397) & \text { NA } \\ 2004 & & 244(90-532) & 149(41-382) & \text { NA } \\ 2005+ & 6 / 4 & 244 & \end{array}$

Conclusions: In this first ever population-based evaluation of SCD in sarcoidosis, patients are not at increased risk for SCD (all sub-types). These findings may reflect actual risk, but estimates may be affected by low statistical power. Future studies may further elucidate the risk and nature of cardiac death among patients with sarcoidosis.

Disclosure of Interest: None declared

DOI: 10.1136/annrheumdis-2018-eular.5530

\section{THU0635 PREGNANCY OUTCOMES IN MIXED CONNECTIVE TISSUE DISEASE: RESULTS FROM A MULTICENTRE COHORT STUDY}

M. Radin ${ }^{1}$, K. Schreiber ${ }^{2}$, M. Cuadrado ${ }^{2}$, I. Cecchi ${ }^{1}$, A. Laura ${ }^{3}$, F. Franceschini ${ }^{3}$, T. Caleiro ${ }^{4}$, E. Gibbone ${ }^{5}$, M. Khamashta 6 , J. Buyon ${ }^{7}$, P. Izmirly ${ }^{7}$, M. Aguirre $Z_{\text {Zamorano }}^{8}$, D. Roccatello ${ }^{1}$, L. Marozio ${ }^{5}$, S. Sciascia ${ }^{1} .{ }^{1}$ Università di Torino, Turin, Italy; ${ }^{2}$ Guy's and St Thomas' Hospital, London, UK; ${ }^{3}$ University of Brescia, Brescia, Italy; ${ }^{4}$ Universidade de Sao Paulo, Sao Paulo, Brazil; ${ }^{5}$ Sant'Anna University Hospital, Turin, Italy; ${ }^{6}$ Dubai Hospital, Dubai, United Arab Emirates; ${ }^{7}$ New York University School of Medicine, New York, USA; ${ }^{8}$ University Hospital Reina Sofía, Cordoba, Spain

Background: Mixed connective tissue disease (MCTD) is characterised by signs and symptoms of a combination of disorders, primarily systemic lupuserythematosus (SLE), scleroderma and polymyositis and is characterised by the presence of high titre antibodies to U1-ribonucleoprotein (RNP)

When planning a pregnancy in patients with connective tissue diseases, ENA profiling is suggested but generally refers to testing for maternal antibodies specifically to components of the SSA/Ro-SSB/La ribonucloprotein complex since these have been associated with foetal cardiac conduction abnormalities and neonatal skin rashes. Nevertheless, little is known about the maternal and foetal pregnancy outcomes in women with the presence of anti-U1RNP antibodies absent reactivity to SSA/Ro-SSB/La

Objectives: We aimed to investigate foetal and maternal pregnancy outcomes from a large multicentre cohort of MCTD women.

Methods: Data was retrospectively collected from S. Giovanni Bosco Hospital and Sant' Anna University Hospital, Turin, Italy, the Lupus Unit, Department of Rheumatology at St Thomas' Hospital, London, UK, Hospital das Clínicas da Faculdade de Medicina daUniversidade de Sao Paulo, Sao Paulo, Brazil, Hospital Reina Sofia de Córdoba, Spain, ASST SpedaliCivili di Brescia, Brescia, Italy. Inclusion criteria included: Women ever pregnant who fulfilled the established criteria of MCTD with confirmed anti-U1RNP positivity.

Results: This multicentre retrospective cohort study describes the foetal and maternal outcomes of 203 pregnancies in 94 consecutive women ever pregnant (mean age at data collection 45.1 years old, S.D. 10.9; mean disease duration a data collection 12.9 years, S.D. 8.5). Demographic, clinical and laboratory characteristics are summarised in table 1 . Of the 203 pregnancies analysed the foetal outcomes were as follows: $146(71,9 \%)$ resulted in live births, $38(18,7 \%)$ in miscarriages, $18(8,9 \%)$ in stillbirths (after 20 weeks gestation) and eleven $(5,4 \%$ cases showed intrauterine growth restriction (IUGR). Maternal pregnancy outcomes were as follows: eight $(3,9 \%)$ cases developed pre-eclampsia, two $(0,9 \%$ cases developed eclampsia, 31 (15,3\%) women developed gestational hypertension and three $(1,5 \%)$ cases were diagnosed with gestational diabetes. Moreover, we report a case of complete congenital heart block $(0,45 \%)$ and a case of skin rash in consecutive offspring born to a mother with anti U1RNP antibodies in the absence of anti-Ro/SSA-SSB/La antibodies.

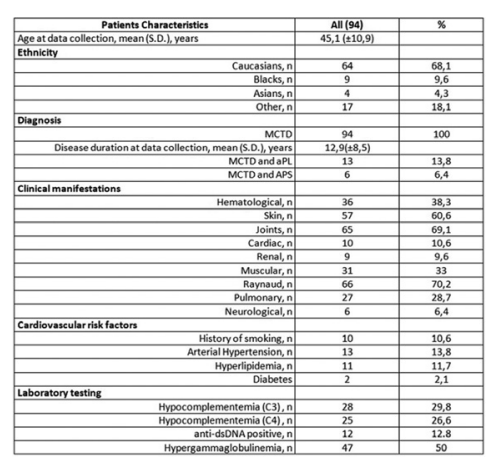

Conclusions: The observed live-birth-rate was as high as $72 \%$, with poorer foetal outcomes observed in MCTD women with antiphospholipid antibodies and 